\title{
Sistematização de uma experiência agroecológica no Cerrado brasileiro: subsídios para o planejamento de unidades produtivas de bases ecológicas
}

\author{
Isabel Corrêa Fontes Chagas de OLIVEIRA ${ }^{1}$, Renato Linhares de ASSIS2*, \\ Adriana Maria de AQUINO2 \\ 1 Associação de Agricultura Ecológica, Brasília, DF, Brasil. \\ ${ }^{2}$ Embrapa Agrobiologia, Seropédica, RJ, Brasil. \\ *E-mail: renato.assis@embrapa.br \\ (ORCID: 0000-0002-8553-5551; 0000-0003-4228-5166; 0000-0003-3718-4512)
}

Recebido em 01/12/2021; Aceito em 16/12/2021; Publicado em 18/12/2021.

\begin{abstract}
RESUMO: Este estudo consiste na sistematização de uma experiência agroecológica a partir do ordenamento e síntese dos processos do seu uso e ocupação. A experiência iniciou em 1984, em unidade agroecológica pioneira, com características neorurais, na região Centro-oeste do Brasil. A pesquisa contou com entrevistas não estruturadas, levantamento de campo, pesquisa bibliográfica e documental (fotografias, revistas, jornais, imagens de satélite e fotografias aéreas). Utilizou-se a ferramenta Google Earth para avaliar o mosaico de agroecossistemas resultante da ação agroecológica no espaço e tempo. Os resultados apontaram uma dinâmica complexa do processo de construção de agroecossistemas e redes sociais, configurando-se num desenho agroecológico que ultrapassa as fronteiras físicas da propriedade. O processo de síntese e análise relatado, além de empoderar os protagonistas, traz a luz do conhecimento científico aprendizados de uma experiência empírica de um modo de vida integrado à natureza, com riqueza em variedade, diversidade e possibilidades nos processos biológicos, sociais, econômicos, éticos, morais e culturais, que pode inspirar e subsidiar outras iniciativas de base agroecológica.
\end{abstract}

Palavras-chave: neoruralidade; gerenciamento agroecológico; redesenho da paisagem; agroecossistemas.

\section{Systematization of an agroecological experience in the Brazilian Cerrado: subsidies for the planning of productive units of ecological bases}

\begin{abstract}
This study consists of the systematization of an agroecological experience from the ordering and synthesis of the processes of its use and occupation. The experience began in 1984, in a pioneering agroecological unit, with neorural characteristics, in the Midwest region of Brazil. The research included unstructured interviews, field surveys, bibliographic and documentary research (photographs, magazines, newspapers, satellite images, and aerial photographs). The Google Earth tool was used to evaluate the mosaic of agroecosystems resulting from agroecological action in space and time. The results pointed toward a complex dynamic of the construction process of agroecosystems and social networks, configuring itself in an agroecological design that goes beyond the physical boundaries of the property. The reported process of synthesis and analysis, in addition to empowering the protagonists, brings to light scientific knowledge learning from an empirical experience of a way of life integrated with nature, with a wealth of variety, diversity, and possibilities in biological, social, economic, ethical, moral and cultural processes, which can inspire and subsidize other agroecological initiatives.
\end{abstract}

Keywords: neorurality; agroecological management; landscape redesign; agroecosystems.

\section{INTRODUÇÃO}

A sistematização de experiências agroecológicas bem sucedidas se configura como estratégia para que as práticas ecológicas e conhecimentos empíricos, obtidos da experimentação, construção e reconstrução das paisagens agroecoprodutivas, sejam disponibilizados, de modo que colabore com o a construção do arcabouço teórico agroecológico e inspire outras experiências agroecológicas, favorecendo o desenvolvimento do movimento agroecológico.

Para Simon (2007), a sistematização de experiências produz um novo conhecimento, possibilita a generalização, converte a própria experiência em objeto de estudo e de interpretação teórica e, ao mesmo tempo em objeto de transformação, e que ao sistematizar as pessoas recuperam de maneira ordenada o que já sabem sobre sua experiência, descobrem o que não sabem sobre ela e o que não sabiam que já sabiam.

A prática de sistematizações tem relevância crescente e apoia a valorização de saberes locais (ECKERT, 2009). A carência de informações sobre a sistematização está ligada, principalmente, à insuficiência metodológica relacionada às propostas de ação, de forma que a construção do método a ser aplicado é, sem dúvida, a parte mais desafiadora do trabalho (SIMON, 2007).

Com esse entendimento, o objetivo desse artigo é apresentar sistematização da experiência agroecológica do sítio Alegria (pioneira no Distrito Federal), trazendo à luz do conhecimento científico os resultados de experimentos 
práticos da agroecologia, aplicados cotidianamente como um modo de vida. As principais práticas e aprendizados que orientaram para a sustentabilidade desta experiência, proporcionando maior eficiência produtiva e energética, foram ordenados e apresentados sinteticamente.

Por se tratar de uma experiência agroecológica com grandes potenciais e conhecimentos acumulados, a sistematização do seu desenvolvimento produtivo agrícola e das atividades paralelas que a envolvem, além de favorecer a própria experiência sistematizada, a partir da autoanálise e das tomadas de decisões mais acertadas, contribui positivamente com a construção da agroecologia e com a problemática do desenvolvimento rural sustentável, (HOLLIDAY, 1996).

A sistematização de experiências produz um novo conhecimento, possibilita a generalização, converte a própria experiência em objeto de estudo e de interpretação teórica e, ao mesmo tempo em objeto de transformação (SIMON (2007). Além disso, o conhecimento gerado colabora com o relato que destaca a importância da agroecologia para a promoção do desenvolvimento rural sustentável (AZEVEDO; ALMEIDA NETO, 2015)

Entretanto, em função da complexidade das atividades praticadas no tempo em uma experiência agroecológica, além da carência metodológica para esse tipo de sistematização, algumas informações deixam de ser registradas ficando ainda por serem observadas e compartilhadas posteriormente. Portanto não se pretende aqui esgotar os conteúdos que envolvem a experiência analisada. Porém, entende-se que sua sistematização potencializa os conhecimentos adquiridos empiricamente a partir de uma espiral ascendente, que culmina com a intencionalidade de compartilhar os aprendizados.

\section{MATERIAL E MÉTODOS}

A experiência agroecológica sistematizada no período de 1984 até 2012 foi a do sítio Alegria/DF, localizado em Brazlândia, Região Administrativa IV (RA IV) do Distrito Federal, no extremo noroeste, à $50 \mathrm{~km}$ de Brasília/DF. O sítio Alegria é o $24^{\circ}$ lote da gleba $n^{\circ} 1$ do assentamento rural pertencente ao Programa Integrado de Colonização Agrícola Alexandre Gusmão (PICAG) do INCRA-DF. Está localizado nas coordenadas geográficas 15³8'35.19"S e $48^{\circ} 09^{\prime} 45.54^{\prime \prime} \mathrm{O}$, situado nas proximidades das ocupações urbanas de Brazlândia, a $3,5 \mathrm{~km}$ de estrada de terra à Nordeste dessa localidade.

O processo de experimentação e construção do modelo agroecológico do sítio Alegria se iniciou em 1984. Nele os agroecossistemas amadureceram paralelamente ao desenvolvimento de relações sociais mais justas aliados à conservação ambiental da região onde se encontra. Fez parte do desenvolvimento dos agroecossistemas a organização coletiva com outros produtores para venda direta aos consumidores, o engajamento local, político, econômico e ambiental e o fortalecimento das relações com as instituições públicas e privadas, dentre elas as organizações do terceiro setor. Portanto, a experiência em questão possui fronteiras além dos limites da unidade de produção, com rede intricada de relações que garantem sua sustentação.

O desenvolvimento agrícola da experiência está diretamente associado ao desenvolvimento de outros serviços ambientais de caracteres multidisciplinares. Serviços estes desde o turismo ecológico e pedagógico, capacitações técnicas de profissionais e agricultores familiares, o recebimento de estagiários de escolas técnicas e parcerias com instituições de pesquisas e ensino.

Para sistematizar essa experiência agroecológica foi utilizada como base a metodologia proposta por Holliday (1996), chamada por metodologia de cinco tempos, que são: o ponto de partida, as perguntas iniciais, a recuperação do processo vivido, a reflexão de fundo e os pontos de chegada. Entretanto, como o próprio autor explicita a proposta não busca ser um "receituário", mas sim um instrumento utilizável, com algumas pautas indicativas que, se posta em prática permitirá o seu questionamento, modificações, enriquecimento e adaptação às condições particulares de cada um. Ainda complementa que embora a proposta, em cinco tempos, sugira um procedimento com uma ordem justificada, este não deverá seguir-se exatamente como proposto, pois dependerá de muitos fatores que incidem na multiplicidade de experiências existentes.

Segundo o mesmo autor, a sistematização de experiência constitui interpretação crítica de uma ou várias experiências que, a partir de seu ordenamento e reconstrução, descobre ou explicita a lógica do processo vivido. São considerados os fatos que interviram no processo, a forma como se relacionaram entre si e porque o fizeram do respectivo modo, buscando compreender e tratar com o qualitativo da realidade que se encontra em cada situação particular (HOLLIDAY, 1996).

A elaboração dessa sistematização contou com pesquisas bibliográficas, documentais e levantamentos de campo. Utilizou-se no levantamento de campo de entrevistas semiestruturadas - com os atores, parceiros e afins, registros fotográficos e ainda um mapeamento participativo junto aos atores da experiência, o que permitiu o desenho das atividades agroecológicas do local, no tempo e espaço em imagens de satélites do Google Earth, sobrepostas por fotografias aéreas antigas acessadas na Companhia de Desenvolvimento Habitacional do Distrito Federal.

\section{RESULTADOS}

O sítio Alegria constituiu um mosaico de uso produtivo da propriedade resultante da aplicação contínua e diversificada de práticas e atividades agroecológicas desenvolvidas no período de 28 anos de experiência. Esse mosaico de atividades ilustra a complexidade alcançada pela construção agroecológica no tempo. A unidade de produção em questão possui grande potencial produtivo e inspirador, pois ao mesmo tempo que utiliza os recursos naturais envolvidos, reconstitui, conserva o meio ambiente e difunde essa prática. $\mathrm{Na}$ região onde se encontra, Centro-Oeste brasileiro, é a unidade de produção agroecológica mais antiga em contínua atuação, configurando-se como uma das mais consolidadas e também reconhecidas em Brasília-DF. O sítio serve como local de moradia familiar, produção, consumo e distribuição de alimentos e matérias primas com alto valor biológico à cidade. $\mathrm{Na}$ Figura 1 pode-se observar um fluxograma generalizado das atividades envolvidas na experiência do sítio Alegria.

\subsection{Contextualização histórica da experiência}

Essa experiência foi idealizada e concretizada por um casal de Engenheiros Agrônomos, motivados pela vontade e necessidade de mais ecologia em suas realidades socioambientais. Assim, em 1984 o casal adquiriu uma propriedade com água em abundância, fácil acesso, 
proximidade ao mercado consumidor, mas o solo apresentava baixíssima fertilidade, que com energia física e mental, se transformaria no sítio Alegria.

O casal protagonista se conheceu em 1977, na Universidade Federal Rural do Rio de Janeiro (UFRRJ), em um contexto histórico de fortalecimento dos movimentos sociais, durante a ditadura militar, e do estabelecimento da industrialização da agricultura brasileira, a chamada
Revolução Verde ${ }^{1}$. Durante o curso de Engenharia Agronômica se articularam ao movimento de agricultura alternativa que questionava as imposições técnicas da "agricultura moderna", como os chamados "pacotes agrícolas" e a intensa mecanização do campo. Esse movimento, de modo geral em contracorrente, cresceu, distribuiu-se, multiplicou-se e é precursor do que hoje conhecemos como Agroecologia.

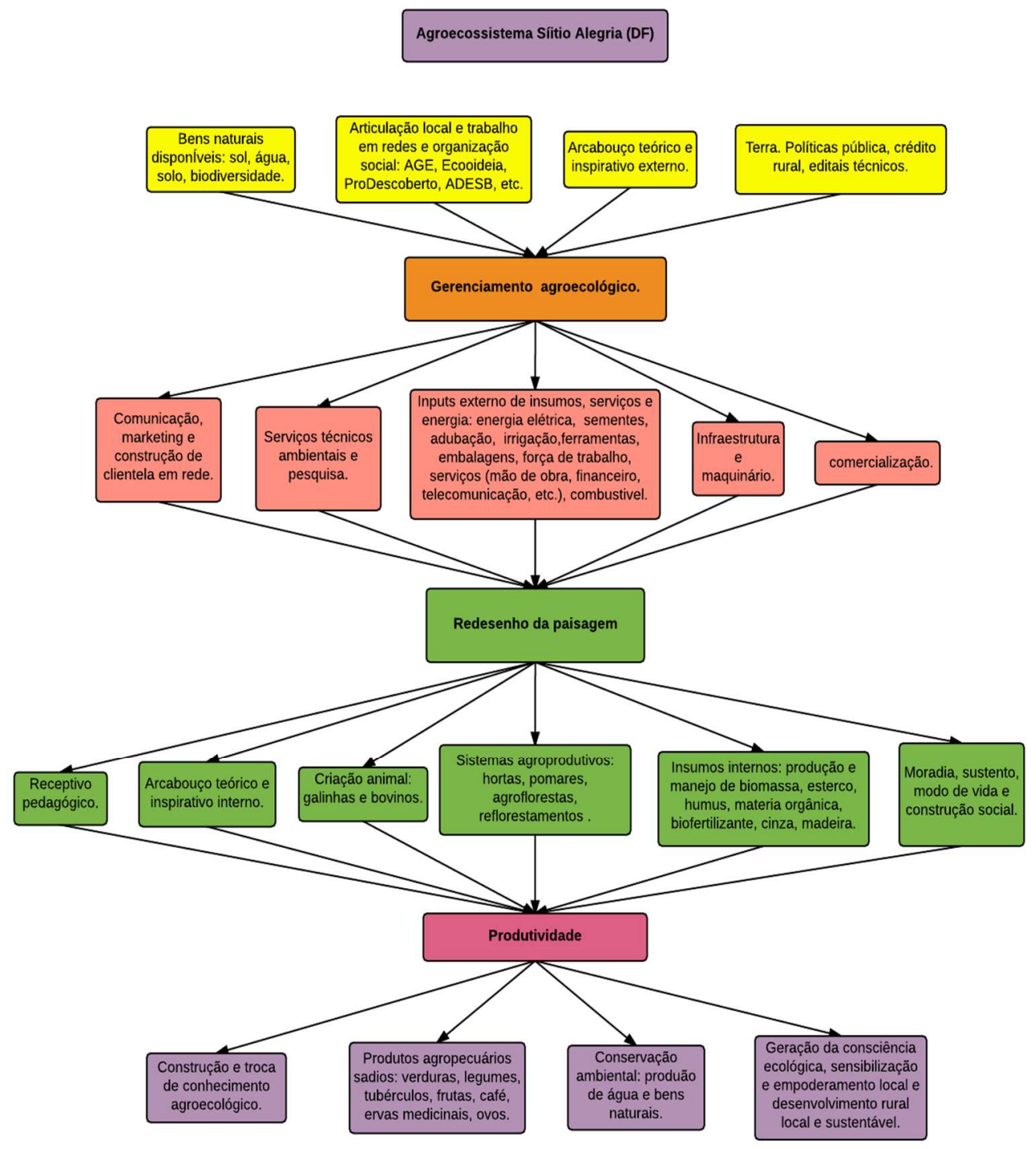

Figura 1. Fluxograma de atividades envolvidas na experiência do sítio Alegria.

Fonte: pesquisa de campo.

Figure 1. Flowchart of activities in the the Alegria farm experience.

Source: field research.

\subsection{Aspectos socioambientais da região}

O local escolhido foi Brazlândia, cinturão verde do Distrito Federal localizado no seu extremo noroeste. Além de estar próximo à importante mercado consumidor, a região insere-se em importante bacia hidrográfica, responsável por aproximadamente $65 \%$ da água consumida em Brasília. Por isso toda a região foi definida como Área de Preservação Ambiental (APA) da bacia hidrográfica do rio Descoberto.

1 "Pode-se caracterizar a Revolução Verde como um paradigma tecnológico derivado da evolução dos conhecimentos da química e da biologia, que definiram uma trajetória tecnológica baseada no uso intensivo de insumos químicos. Essa modernização na
Essa abundância hídrica foi determinante na escolha do local pelos protagonistas.

A região faz divisa com o Parque Nacional de Brasília e apresenta belas paisagens naturais, muitas propriedades agrícolas e outras áreas públicas destinadas à preservação e conservação ambiental. Brazlândia, ainda conserva uma cultura rural peculiar. Em decorrência da presença dos elementos naturais mencionados, que exigem maior responsabilidade ambiental, existem em Brazlândia estruturas 
sociais organizadas e orientadas ao desenvolvimento sustentável da região, como é o caso da Associação de Desenvolvimento Sustentável de Brazlândia (ADESB), e da Associação dos produtores da Bacia do rio Descoberto (Pro Descoberto).

\subsection{Aspectos ambientais da unidade de produção agroecológica}

A propriedade possui 28 ha e é delimitada por dois córregos componentes da microbacia do córrego Capão da Onça e pela Floresta Nacional de Brasília (FLONA-DF), o que assegura abundância hídrica e significativa proteção ambiental ao local.

O bioma local é o Cerrado, com o clima caracterizado por duas estações bem marcantes, verão quente e úmido e inverno frio e seco, com temperaturas variando entre $7^{\circ} \mathrm{C}$ mínima e $35^{\circ} \mathrm{C}$ máxima, com média de $22^{\circ} \mathrm{C}$. A região apresenta um regime pluviométrico que varia entre 1800 a $2000 \mathrm{~mm}$ ao ano. Esta variação pluviométrica refere-se principalmente ao período chuvoso, pois não há chuva no período de seca que predomina dos meses entre abril e agosto. A vegetação natural existente é composta, principalmente, por campos limpos e rupestres, uma fitofisionomia bastante ocorrente no planalto central brasileiro. A altitude média do sítio é de aproximadamente $1100 \mathrm{~m}$. A Geologia é representada predominantemente por cambissolos, pequenas manchas de latossolos e solos aluvionários ao longo dos cursos d'água.

A geomorfologia da propriedade apresenta características de recarga hídrica, conformando-se, em sua maior parte, por um conjunto de morros divididos por drenagens, de primeira ordem, formadoras dos dois córregos delimitadores da propriedade. A menor parte é formada por áreas mais planas e passíveis de agricultura de baixo impacto, devido à sensibilidade geomorfológica e a importância dos recursos naturais locais, especialmente os hídricos. O restante compõe-se de Áreas de Preservação Permanente de corpos hídricos.

Esses elementos ambientais expressam uma peculiaridade de sucesso a essa unidade produtiva, caracterizada pela dinamicidade de uso e ocupação no tempo e espaço. Pois, ainda que a área com aptidão agrícola fosse restrita, devido à baixa fertilidade natural dos solos, os fatores como o potencial hídrico, acesso e proximidade ao mercado consumidor, aliados a capacidade de gestão e gerenciamento, garantiram o desenvolvimento contínuo e progressivo do fazer agroecológico, pois desafios como a falta de energia elétrica e telefone, por exemplo, não faltaram.

\subsection{Organização social e atividades agregadas}

O casal protagonista da experiência em análise adquiriu a propriedade, paralelamente ao desenvolvimento de outras atividades profissionais. Instalaram as estruturas básicas de moradia e de produção e se mudaram para o local com a família. Desde então iniciaram o desenho e redesenho de uma paisagem agroecológica bastante diversa e dinâmica. Uma paisagem que vai além da diversidade em agroecossistemas, sendo composta, também por uma multiplicidade de usos e redes sociais.

Inicialmente, em função do trabalho vinculado às áreas de conservação e preservação ambiental do então Instituto Brasileiro de Desenvolvimento Florestal (IBDF), o marido se deslocava diariamente para Brasília, enquanto a esposa, como funcionária de um órgão educacional do distrito federal, passou a trabalhar em escola rural próxima à propriedade. Esse fato foi fundamental para o melhor acompanhamento da instalação das estruturas e plantios iniciais.

O contato direto do casal protagonista com o urbano favoreceu o entrosamento com outros ativistas engajados ao movimento de agricultura alternativa, e contribuiu para estruturar as bases política, econômica e social do casal, bem como para a atuação desses no fortalecimento do próprio movimento. Esse entrosamento foi fundamental no estabelecimento de importantes redes sociais que possibilitaram, em 1988, criar a Associação dos Produtores Agroecológicos - AGE, fundamental para a promoção e comercialização de seus produtos em feiras orgânicas distribuídas em Brasília.

A relação campo versus cidade da experiência está enraizada no seu próprio desenvolvimento, ou seja, desde as relações de trabalho, políticas e comerciais, até ao cotidiano familiar, o qual também precisou se adaptar a uma dinâmica social de integração constante do urbano com o rural. Isso ocorreu de forma não planejada, atraindo simpatizantes da Agroecologia e fortalecendo a proposta. Nesse processo, as redes sociais das relações cotidianas, familiares e locais, foram e são as que mais deram suporte e subsídios ao desenvolvimento da proposta agroecológica e da localidade.

Em 2001, o marido licenciou-se do serviço público e se dedicou à consolidação de uma cooperativa de serviços ambientais, ECOOIDEIA, por meio da qual passou a prestar serviços de consultorias nas mais diversas temáticas ambientais, especializando-se em gerenciamento e gestão de resíduos sólidos urbanos e agroecologia. A esposa permaneceu no serviço público voltado à educação, até se aposentar, concomitantemente participando dos trabalhos junto a essa nova estrutura social, da qual também foi fundadora, especialmente em ações com educação ambiental e agroecologia, por vezes associadas à estrutura do próprio sítio Alegria.

A atuação então concomitante junto a ECOOIDEIA e a AGE favoreceu o desenvolvimento de uma rede social, que bem articulada e gerida, potencializou a proposta agroecológica da experiência, em que as principais atividades desenvolvidas constituídas foram: produção de hortigranjeiros, cursos, visitas técnicas e ecoturismo (Figura 2).

As atividades de caráter social: ecoturismo, visitas técnicas e cursos, foram sendo agregadas à prática agroecológica da experiência à medida que novas estruturas físicas e sociais se consolidaram e novos conhecimentos e aprendizados foram adquiridos com a prática, contribuindo para a geração da renda familiar e sustentabilidade da experiência. Assim, a prática de atividades não agrícolas diversas, complementando a renda gerada pela produção agropecuária, sempre esteve presente nessa experiência, sendo aprimorada com o tempo a partir de vivência e experimentação.

As atividades voltadas ao ecoturismo foram sendo agregadas à medida que demandas espontâneas surgiram, mas para sua consolidação foram necessários alguns investimentos em infraestrutura (Figura 2) e ajustes na dinâmica familiar, pois a abertura do sítio para o recebimento de turistas exigiu adaptações também de relacionamentos com este novo público consumidor e com a própria nova atividade econômica agregada. 

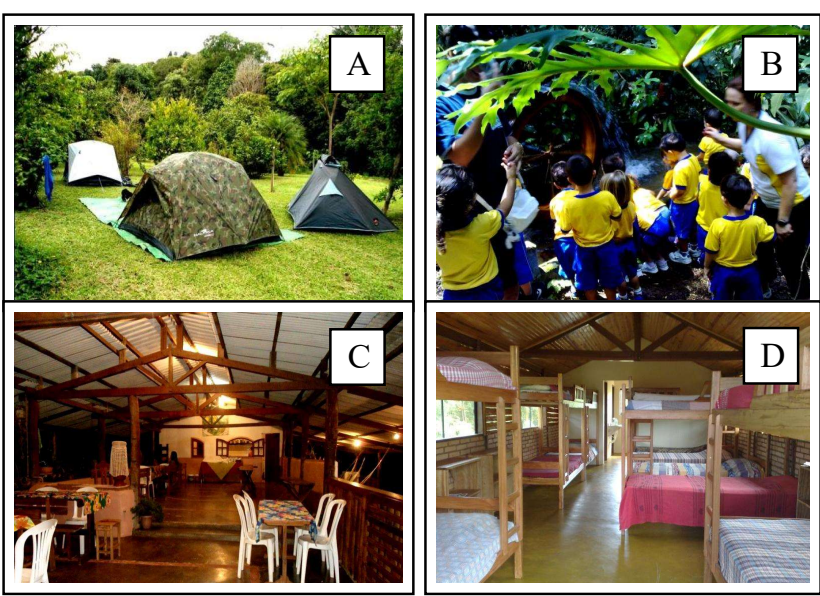

Figura 2. Ajustes na infraestrutura para o turismo e sua dinâmica no sítio Alegria: (A) turismo integrado ao pomar; (B) atividade pedagógica; (C) adaptação de infraestrutura utilizada como curral para servir como espaço de recepção de visitantes, equipada com cozinha e banheiros; (D) alojamento com mobiliário produzido com madeira de eucalipto produzido na unidade de produção.

Fonte: arquivo do sítio Alegria.

Figure 2. Adjustments in the tourism infrastructure and its dynamics in the Alegria farm: (A) tourism integrated with the orchard; (B) pedagogical activity; (C) adaptation of infrastructure used as a corral to serve as a visitor reception area, equipped with a kitchen and bathrooms; (D) accommodation with furniture produced with eucalyptus wood produced in the production unit. Source: Alegria farm archive.

\subsection{Infraestrutura básica}

A propriedade foi adquirida com um "barraco", sem energia e saneamento, com uma pequena captação de água no córrego, com pontos erodidos e com intenso desmatamento devido à prática da carvoaria realizada antes da aquisição do terreno. Uma das primeiras medidas foi a contratação de um empregado que se dispusesse a morar no "barraco" e pudesse colaborar na construção de infraestrutura básica.

$\mathrm{O}$ que se dispunha inicialmente era de um pequeno capital financeiro e muita vontade e determinação para materializar a proposta agroecológica; planejamento básico de uso e ocupação do território para curto, médio e longo prazo, de modo que a aliança entre a produção agropecuária, a recuperação e conservação ambiental fosse sempre mantida e otimizada por meio de uma gestão integrada e eficiente.

Como resultados, em 1986, embora ainda sem energia elétrica, já havia uma boa malha de captação e distribuição de água por gravidade, tanto para uso doméstico como para o uso agropecuário; galpão multifuncional; casa sede de moradia da família; sistema agroprodutivo que já atendia grande parte da demanda alimentar da família e gerava excedentes para comercialização.

\subsection{Captação, uso e conservação da água}

No primeiro momento houve aproveitamento e melhoramento do pequeno canal preexistente, e posteriormente realizado o desenho e construção de uma malha hídrica, com melhor funcionalidade para distribuição de água na unidade de produção. Inicialmente o abastecimento e a irrigação eram por gravidade, com aspersão de baixa pressão, sendo o bombeamento da água para uso e consumo por roda d'água bastante eficiente, com potencial hidráulico suficiente à demanda de uso inicial do sítio Alegria.

Em 1991, com a maior experiência dos protagonistas associada a melhor infraestrutura da propriedade e ao contexto de uma conjuntura política e socioambiental mais favorável, foi possível obter recurso financeiro de crédito rural, e assim instalar energia elétrica e construir dois tanques de água para irrigação, juntamente com um sistema de irrigação mais eficiente, com bombas elétricas de irrigação e uma complexa malha de canos. Esse novo sistema de irrigação substituiu paulatinamente o sistema por gravidade, que permaneceu na dinâmica de desenvolvimento e aprimoramento constante às novas demandas do sítio Alegria, com adaptações como a instalação de uma segunda bomba junto à roda d'água, para aumentar sua eficiência energética, e a construção de uma segunda caixa d'água com capacidade de 30.000 litros para melhor atender a demanda da propriedade. O manejo da água e cuidados com o saneamento, além dos plantios permanentes de espécies nativas e produtivas nas margens dos córregos, têm contribuído para a necessária conservação in sito da água até os dias atuais.

\subsection{Manejo, uso e conservação do solo}

No sítio Alegria alguns cuidados com o solo foram realizados antes mesmo da família se mudar para o local, como por exemplo, a identificação de áreas com erosão ou em estados sensíveis a deslizes e perdas de solo, como prioritárias para ações de remediação ou prevenção.

Embora inicialmente tenha sido realizada uma análise da fertilidade química dos solos das diferentes glebas, de forma a orientar a calagem e consecutivos aportes de adubos orgânicos, a baixa aptidão agrícola dos solos relacionada a uma baixa atividade biológica dos solos, apresentou-se como um elemento de dificuldade para a atividade produtiva. Só era possível encontrar solos com material orgânico nas camadas superficiais nas margens dos córregos, caracterizadas como de aluviões, mesmo assim esses locais estavam bastante desmatados.

Porém, considerando a abundância hídrica local, associada à gestão atenta e criativa com uso de bastante mão de obra, esse problema foi contornado com o manejo orgânico da unidade de produção como um todo. Assim, a maior parte da base produtiva dos solos do sítio Alegria foi formada a partir da aplicação intensiva de matéria orgânica rica em atividade biológica e de diversos manejos agroecológicos, com caracteres variados, conforme as necessidades e possibilidades de cada momento.

Ao analisar os tipos e intensidade de adubação orgânica utilizada ao longo do tempo, verifica-se que a (re)construção da atividade biológica dos solos possui linha ascendente de crescimento. A percepção da família é de que à medida que o solo foi sendo protegido das intempéries climáticas, recebeu a incorporação de biomassa e água, o desenvolvimento biológico foi favorecido, tornando-o mais fértil.

Desse modo, o processo de regeneração, construção e conservação do solo da experiência em questão possui um histórico considerável de correções, experimentações, adaptações e manejos produtivos variados como: correções de erosões; plantios diversificados, no tempo e espaço, de diferentes espécies e variedades; promoção constante da reciclagem de nutrientes e de matéria orgânica com estratégias como adubação verde e compostagem; e integração das produções animal e vegetal. 
Nessa experiência a adubação é realizada desde seu início com a aquisição e aproveitamento de recursos internos e externos à unidade produtiva: podas e aparas de jardinagem urbana; estercos de animais coletado nas pastagens; produção e manejo de biomassa vegetal local; produção de cinza; produção e compra de esterco animal; compostagem com biomassa e resíduos orgânicos tais como sobras de feiras, estercos, cinzas, resíduos de colheitas e parte dos resíduos orgânicos domésticos. A produção e uso de biofertilizantes sempre foi utilizada como adubação complementar e de forma a maximizar a pequena quantidade de esterco produzida no sítio.

O input de resíduos da jardinagem urbana e a coleta de estercos em pastagens, sempre foi alternativa para aumentar a atividade biológica do solo, notadamente no período inicial da experiência em que a demanda por matéria orgânica era alta e a disponibilidade dentro da unidade de produção era baixa. Assim, no processo dinâmico do uso, manejo e (re)construção do solo, várias fontes de adubação têm sido utilizadas, dependendo da disponibilidade local, para melhor atender as demandas produtivas.

O manejo continuado de gramíneas, utilizadas como biomassa vegetal para cobertura morta e produção de compostos, foi a principal prática agroecológica relacionada à nutrição das plantas utilizada, tanto diretamente junto à base das plantas, em formato de anéis, como em pequenos montes, visando à eficiência energética da adubação in loco. Com essa estratégia de manejo tem sido proteger as raízes das plantas, conservar umidade, favorecer a maior atividade biológica e ciclagem de nutrientes.

A essa estratégia de adubação acrescenta-se que, dependendo da necessidade, pode-se recorrer à complementação com biofertilizante líquido e incrementá-la com o plantio consorciado de leguminosas para adubação verde visando o aporte de nitrogênio no sistema produtivo.

No desenvolvimento dos processos agroecológicos da unidade produtiva utilizou-se microtrator e roçadeiras, principalmente costal. Mais recentemente, com melhor estabilidade financeira, foi possível adquirir um pequeno trator para roçar gramados, que além de potencializar a produção e manejo da biomassa vegetal, possibilita maior eficiência da manutenção da área para o turismo.

\subsection{Regulação biótica e manejo da paisagem agroecológica}

A busca dessa autorregulação é recorrente no sítio Alegria para a promoção do controle biológico conservativo, estratégia principal do manejo fitossanitário local, que inclui ainda o manejo de espécies vegetais atrativas de inimigos naturais, como joaninhas, plantas espontâneas e outras cultivadas exclusivamente com essa finalidade, catação manual de lesmas e lagartas, e práticas com orientações quânticas envolvendo a dinâmica natural dos ecossistemas, promovendo a estabilidade dos cultivos e a saúde dos animais, fechando o ciclo da conservação e regeneração dos recursos naturais. De forma complementar, recorre-se a práticas de controle de impacto mais imediato, como o uso de preparados fitoterápicos, notadamente de pimenta e alho.

No desenvolvimento dos agroecossistemas locais as variáveis tempo e espaço também foram determinantes. O gerenciamento das estratégias de uso e ocupação produtiva se fez presente desde o início da experiência. Inicialmente, como havia muita área desmatada, sem uso agrícola, a prioridade foi recompor as áreas de solos mais férteis, encontradas principalmente às margens dos córregos, o que demandou muita atenção e cuidado para a regeneração e conservação dos recursos naturais locais.

A reestruturação da vegetação permanente com plantios de espécies nativas ocorreu simultaneamente com o desenvolvimento da atividade olerícola e agroflorestal (Figura 3), sendo acrescentadas espécies arbóreas também produtivas como pupunhas e cafeeiros e frutíferas como: bananeiras, lichieiras, mangueiras, caquizeiros, citros, gravioleiras, goiabeiras, maracujazeiros, framboeseiras, entre outras, enriquecendo a biodiversidade produtiva e (re)equilibrando o agroecossistema.
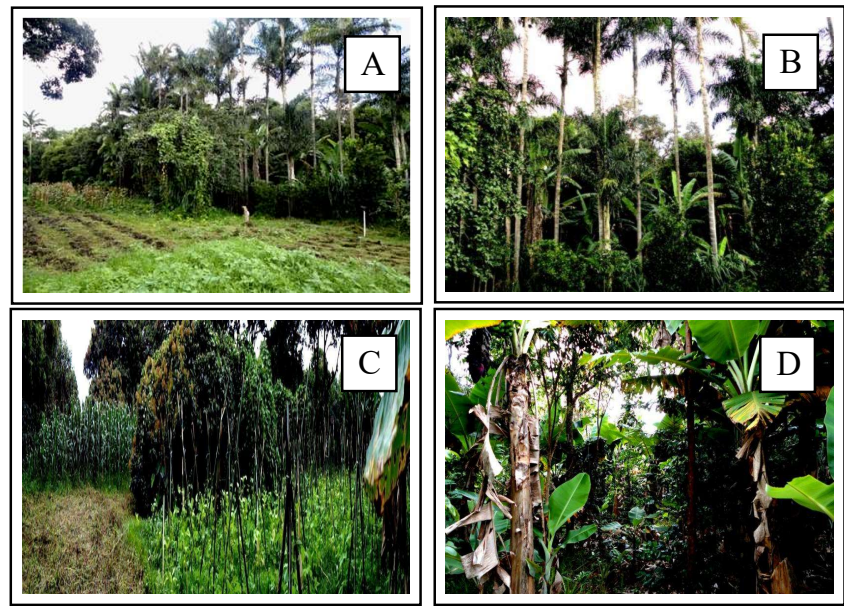

Figura 3. Manejo agroecológico da paisagem no sítio Alegria: (A) diversificação produtiva de hortaliças em limite de área de preservação permanente (APP); (B) APP com sistema agroflorestal (SAF); (C) produção de hortaliças em consórcio com plantas frutíferas; e (D) SAF com espécies nativas e exóticas produtivas.

Fonte: arquivo do sítio Alegria.

Figure 3. Agroecological management of the landscape at Alegria farm: (A) productive diversification of vegetables in the limit of a permanent preservation area; (B) permanent preservation area with agroforestry system; (C) production of vegetables in consortium with fruit plants; and (D) agroforestry system with native and exotic productive species.

Source: Alegria farm archive.

Com a maior autonomia produtiva do sítio Alegria, conquistada pela família aproximadamente a partir de 1998, houve a primeira expansão do sistema produtivo da propriedade, constituindo um pomar diversificado com potencial produtivo e agroecoturístico, ao associar a produção de frutas com área de lazer e jardins.

Atualmente a produção de olerícolas, base de cultivos iniciais implantados para atender as feiras orgânicas da AGE, permanece nos mesmos locais, mas em áreas mais restritas e caracterizada por um conjunto de espécies que demonstraram maior adaptação às condições ambientais locais e de gerenciamento da unidade produtiva, considerando especialmente o contexto dos sistemas agroflorestais em áreas de preservação permanente (APPs) e suas áreas limítrofes, bem como o cultivo de espécies mais tolerantes à sombra e a convivência com plantas espontâneas, evitando o uso de canteiros, que eram muito utilizados inicialmente.

Um aspecto importante de ser mencionado refere-se à produção madeireira para manutenção da infraestrutura e aproveitamento dentro da propriedade. $\mathrm{Na}$ unidade produtiva em questão a composição da paisagem com cultivo 
de eucaliptos em consócio com diferentes espécies arbóreas como ipê, angico, café e frutífera diversificadas, fornece a madeira necessária para o atendimento da manutenção e desenvolvimento do sítio Alegria. Assim, o manejo de corte é adaptado às demandas locais e cumpre papel de planta companheira, proporcionando sombreamento ou insolação quando necessário para as outras espécies.

\subsection{Produção animal}

A dinâmica da produção animal (avicultura e bovinocultura) teve relação tempo e espaço bem definidos a partir de uma gestão agroecológica consciente, variando de intensidade e uso conforme, principalmente, a demanda da produção vegetal por estercos e a disponibilidade de recursos.

Assim, a produção de gado leiteiro e de aves de postura sempre esteve associada prioritariamente à produção de estercos, notadamente no período agroprodutivo inicial que mais demandou a utilização de resíduos orgânicos.

Em 1994, com um contrato de crédito rural, foi possível a ampliação do curral para a melhor estruturação da produção. Porém, após 15 anos com essa prática, ela deixou de fazer parte do desenho produtivo da propriedade em função da alta exigência de cargas de trabalho e também pela redução da demanda por estercos, que ocorreu à medida que aumentou a produção de biomassa vegetal, em decorrência do avanço do manejo agroecológico na unidade de produção como um todo, que deixou de ser dependente de altos aportes de estercos demandados inicialmente.

Com esse novo quadro de baixa demanda por estercos, gerencialmente optou-se por encerrar a atividade de bovinocultura no sítio Alegria e passar a adquirir, eventualmente de pequenos produtores de leite localizados próximos a unidade de produção, pequenas quantidades de estercos que ainda se fazem necessárias.

Com o fim da criação de gado, a infraestrutura utilizada para confinar o rebanho e as áreas de pastagem, passaram por transformações em seus usos. Assim, o curral foi adaptado de forma a se tornar espaço de recepção, com cozinha, e as áreas de pastagem foram substituídas por novos agroecossistemas que passaram a fazer parte de um novo redesenho produtivo da unidade agroecológica.

No que se refere à avicultura de postura, a infraestrutura disponibilizada para o crescimento dos pintinhos sofreu várias modificações no tempo, as quais possibilitaram reduzir a taxa de mortalidade das aves de $30 \%$ para $5 \%$. Os locais escolhidos, entretanto, mantiveram as características de sombreamento natural e disponibilidade de pasto para as aves dividido em piquetes. A alimentação das aves sofreu algumas pequenas alterações, como a germinação do grão de milho antes de servi-lo aos animais. Contudo, práticas como o aproveitamento das sobras de hortas, das feiras e do preparo de alimentos nos domicílios da unidade de produção, bem como o fornecimento de ração preparada localmente com mistura de farelos de grãos, fazem parte dessa atividade desde o início, possibilitando o retorno produtivo com ovos e estercos.

\subsection{Produção de mudas}

A produção de mudas, tanto de espécies olerícolas como frutíferas, madeireiras e ornamentais, é realizada localmente, utilizando-se substrato preparado na unidade de produção a partir da mistura de terra preta, cinzas, areia do córrego ou palha de arroz, adquirida externamente, e esterco de gado. Para mudas de olerícolas há uma pequena estufa, enquanto que as demais são produzidas em área semicoberta, utilizando espaços do sítio com sombreamento natural.

Essa estratégia de produção de mudas é prática rotineira na unidade de produção em questão, e garante quase totalmente o atendimento da demanda por materiais propagativos do sistema de produção como um todo. Porém, eventualmente ainda se faz necessário adquirir externamente mudas de determinadas espécies e sementes.

\subsection{Prevenção de incêndios}

No que tange prevenção de incêndios, a agregação social local constituiu-se em fator fundamental para o sucesso da iniciativa, e ocorreu de forma gradual e progressiva a partir de vivências e aprendizados coletivos. Isso ocorreu a partir de perdas e danos que fizeram a comunidade passar a se reunir para discutir o problema e buscar estratégias coletivas para minimizar os prejuízos decorrentes de incêndios, problema recorrente nas áreas agrícolas do cerrado brasileiro.

Atualmente, em períodos de ocorrência de incêndios, a comunidade da microbacia fica atenta aos focos para mais rápida contenção, utilizando abafadores conforme recomendação do Previ-fogo do IBAMA. Entretanto, já houve momentos de bastante desorganização e atritos por diversos motivos, que retardaram a ação de contenção do fogo com grandes prejuízos a atividade de produção agrícola na região.

Destarte, a força humana da comunidade somada ao contato eficiente com bombeiros e IBAMA, tem se mostrado fundamental no combate local a incêndios. A essa experiência comunitária cabe aqui agregar o relato de experiências específicas do trabalho de combate ao fogo no sítio Alegria, que possibilitaram aprendizados obtidos no "calor" das queimadas, como: contrafogo; aceiros; abafadores; e plantio de plantas, como agaves, que contribuem para reduzir a disseminação do fogo.

\section{DISCUSSÃO}

A adaptação agroecológica à localidade sempre ocorreu cotidianamente, por meio da observação, experimentação e integração com a natureza, além do desenvolvimento de práticas agropecuárias ecológicas e de relações sociais criativas, dinâmicas e harmonizadas às especificidades locais no tempo e espaço do desenvolvimento da unidade de produção analisada.

O perfil neorural do casal protagonista foi fundamental no estabelecimento de relações diferenciadas entre produção e consumo, da mesma forma como foi observado por Orria; Luise (2017). Destaca-se o papel de liderança no processo de criação da AGE, a qual possibilitou sucesso na comercialização de seus produtos em feiras orgânicas.

Por sua vez, no que tange as estratégias produtivas. Precisaram conhecer bem a realidade local e investir muito tempo, conhecimento e trabalho no caminho do equilíbrio agroecológico. Embora o casal tenha recebido grandes influências da agricultura e ecologia, potencializadas com os conhecimentos adquiridos na Universidade, eles tiveram que aprender as técnicas e a gestão da experiência agroecológica a partir da experimentação de ideias e de novos conhecimentos, com erros e acertos, agregados de modo "criativo orientado" e reorientado, repetidas vezes, e continuamente aprimoradas com o tempo.

À época das primeiras iniciativas com agricultura orgânica no Brasil, nas décadas de 1970 e 1980, o Estado mantinha-se 
a margem do processo de desenvolvimento das experiências nesse sentido, de forma que esse ocorreu baseado fundamentalmente no esforço de agricultores, em especial com características neorurais. Esses, motivados por convicção ideológica, arcaram com uma fase inicial de intenso aprendizado fundamentada na tentativa e erro (ASSIS; ROMEIRO, 2007; ALVES et al., 2012), constituindo um enredo geral, do começo da produção orgânica no país, que também foi observado no início das atividades do sítio Alegria.

Assim, técnicas das diferentes correntes de agricultura de base ecológica foram experimentadas, o que favoreceu a apropriação do entendimento dos procedimentos mais adequados para, conforme descreve Canuto (2017), possibilitar o desenvolvimento de sistemas biodiversos, e assim viabilizar a implantação e condução de agroecosistemas sustentáveis.

O desenvolvimento de sistemas de produção agroecológicos pressupõe uma dependência mínima de insumos químicos (BOAVENTURA et al., 2018). E, entende-se que o sucesso de iniciativas nesse sentido deriva do equilíbrio entre as plantas, solos, nutrientes, luz solar, umidade e outros organismos coexistentes, e que a conservação e ampliação da biodiversidade dos agroecossistemas compõem princípio fundamental para produzir autorregulação e sustentabilidade (ALTIERI, 2012), sendo a saúde do solo item fundamental para a sanidade das plantas (LOPES et al., 2019).

Curiosamente, o período de início da experiência do sítio Alegria coincide com o período de fortalecimento da Revolução Verde e com o início da redemocratização do Brasil. As políticas de incentivo agrícola se orientavam no país para o modelo industrial com caráter extensivo, exportador, considerado naquele momento como "moderno". Uma conjuntura, portanto, que restringiu bastante o acesso às literaturas sobre agriculturas sistêmicas e conhecimentos técnicos agrícolas alternativos aos da agricultura industrial. (SANTOS; CHALUB-MARTINS, 2012; NODARI; GUERRA, 2015; SOUSA; GOIÁS, 2015; CANUTO, 2017).

Entretanto, é também nesse período que os movimentos sociais começaram a se reorganizar e por mais dificultado que tenha sido o acesso às informações técnicas ecológicas consagradas, de raros volumes e caras importações, as articulações de trocas de informações dentro dos grupos do movimento da agricultura alternativa potencializaram $\mathrm{O}$ clareamento e a práxis agroecológica. A qual, de acordo como Nodari e Guerra (2015), desde o início do século passado, desenvolveu-se no bojo de iniciativas como a da agricultura biodinâmica, cujas bases foram estabelecidas por Rudolf Steiner em 1924, e da agricultura orgânica apresentada por Albert Howard em seu livro An agricultural testament (Um testamento agrícola) em 1943. Posteriormente, ao longo do século XX, outros autores ampliaram a base teórica acerca de sistemas de base ecológica que valorizam o uso da matéria orgânica e os processos biológicos.

Ainda de acordo com os mesmos autores, a agroecologia constitui um paradigma emergente que se contrapõe ao da agricultura industrial, e que se diferencia pela abordagem holística que engloba questões ambientais e humanas. Nesse sentido, nos moldes da experiência aqui analisada, não faz uso de insumos químicos sintéticos, e utiliza grande diversidade genética nos agroecossistemas, bem como propugna o fortalecimento das relações de vizinhança e busca sempre produzir alimentos com alta qualidade biológica e nutricional.

Com a análise da sistematização da experiência agroecológica do sítio Alegria, percebeu-se que a dinâmica de uma unidade de produção agroecológica. desde o início, se dá a partir de um conjunto de fatores que abrangem tanto os aspectos de gestão quanto os aspectos físicos e biológicos locais. Assim, o desenvolvimento de técnicas aplicadas à paisagem produtiva, física e social, ocorreu gradualmente à medida que novas percepções, conhecimentos e relações agregavam-se à realidade dos atores, não necessariamente de maneira linear.

Experimentações consecutivas possibilitaram aos atores responsáveis pela experiência aprofundar o conhecimento sobre as características e potenciais da localidade. Essas experimentações basearam-se em conhecimentos técnicos consagrados e, sobretudo, na observação perceptiva cotidiana da dinâmica socioambiental local, o que incluiu a inclusão de conhecimentos tradicionais, fundamentais para o sucesso de iniciativas agroecológicas (BORSATTO; CARMO, 2013), ao ajudar a encontrar o manejo mais adequado para cada agroecossistema em cada momento da experiência.

Por sua vez, a maneira de atuação e engajamento político e social, dos atores protagonistas, incluindo a construção de redes, que têm papel de destaque na construção de fatores qualitativos importantes para a consecução de estratégias e experiências de desenvolvimento sustentável, orientadas pela agroecologia (LIMA, 2019), contribuiu para fortalecer a proposta do sítio Alegria de integração do espaço rural com o urbano.

A diversificação de cultivos, notadamente como a observada no sítio Alegria que envolve sistemas biodiversos com cultivos anuais e perenes, inseridos em um mosaico de estratégias produtivas e de APPs, possibilita a experiência agroecológica manter processos ecológicos que contribuem para estabelecer a autorregulação dos agroecossistemas, conforme Altieri (2012). Além disso, distribui melhor a força de trabalho, ao longo do ano, viabiliza um mix variado de produtos, que é importante para a comercialização em feiras orgânicas, e constitui aspecto de beleza cênica, fundamental para o desenvolvimento de atividades não agrícolas complementares, como o turismo.

Característica inerente a experiência aqui analisada, a neoruralidade se constitui a partir de um fenômeno que procura resgatar valores quase perdidos da vida no campo, como o contato com a natureza e a simplicidade material, bem como aspectos relacionados a questões ecológicas (DIAS; MAZETTO, 2014). Por sua vez, essas características representam atributos inerentes à paisagem rural, que conferem a estas, valores intangíveis passíveis de serem trabalhados e agregados como mais um "produto" estabelecido ao longo do desenvolvimento da experiência agroecológica do sítio Alegria.

\section{CONCLUSÕES}

A sistematização da experiência do sítio Alegria demonstra a complexidade do processo de implantação e condução de Unidades de Produção Agroecológicas. O relato aqui apresentado apresenta de forma objetiva a subjetividade da dinâmica que existe dentro dessas unidades, com riqueza em variedade, diversidade e possibilidades nos processos biológicos, sociais, econômicos, éticos, morais e culturais. Características estas potencializadas pela flexibilidade, 
conectividade e agregação, articuladas em redes, com consciência, responsabilidade, simplicidade, alegria, energia e adaptação para conduzir os passos coletivamente.

Os aspectos do perfil neorural foram reforçados em praticamente todas as atividades da experiência analisada. A articulação, a construção de redes sociais, a agregação e adaptação de atividades multidisciplinares demonstram o grande potencial transformador inserido nessas expressões ou manifestações agroecológicas.

Entende-se que para a viabilidade de processos de desenvolvimento rural sustentável no país faz-se necessário um esforço na construção de políticas públicas que deem a verdadeira importância e suporte suficiente às manifestações e práticas agroecológicas atuantes, como a aqui sistematizada. Políticas de reforma agrária, por exemplo, que colaborem não só com a permanência dos atuais agricultores rurais no campo, como também o retorno dos que foram expulsos e ainda, que incentive e intensifique o movimento neorural, utilizando estratégias que considerem desde crédito e assistência técnica, até programas de articulação e parcerias com agentes de desenvolvimento rural e outros profissionais que atuam para o desenvolvimento da agroecologia.

A sistematização da experiência trouxe a luz do conhecimento científico aprendizados de uma experiência empírica de um modo de vida integrado à natureza. Esses aprendizados sistematizados têm o potencial de colaborar nas tomadas de decisões da própria experiência sistematizada como para inspirar outras experiências de caráter agroecológico.

A sistematização da experiência do sítio Alegria revelou aprendizados alcançados na prática do cotidiano agroecológico, indicando que as inovações tecnológicas são sempre resultado de inquietações vinda de hipóteses, e abrem um leque de possibilidades e conhecimentos. Destrinchar esse leque permanece como um grande desafio, no entanto a cada sistematização de experiências agroecológicas realizada pode-se gerar subsídios para avançar nesse sentido e inspirar interessados nas práticas agroecológicas de que viver um modo de vida agroecológico é possível quando existe interesse e disposição para se construir uma vida integrada à natureza.

Por fim, a partir desta sistematização de experiência agroecológica pode-se observar a grande importância das políticas públicas como subsídios para o fortalecimento da agroecologia no Brasil. Cada crédito rural adquirido representou um grande salto estrutural e produtivo para esta experiência. Entretanto, observou-se a necessidade de ajustes que considerem o perfil neorural nas políticas que subsidiam a agroecologia.

\section{REFERÊNCIAS}

ALTIERI, M. Agroecologia: bases científicas para uma agricultura sustentável. São Paulo: Expressão Popular; Rio de Janeiro: AS-PTA, 2012. 400p.

ALVES, A. C. de O.; SANTOS, A. L. de S.; AZEVEDO, R. M. M. C. Agricultura orgânica no Brasil: sua trajetória para a certificação compulsória. Porto Alegre: Revista Brasileira de Agroecologia, v. 7, n. 2, p. 19-27, 2012.

ASSIS, R. L. de; ROMEIRO, A. R. O processo de conversão de sistemas de produção de hortaliças convencionais para orgânicos. Rio de Janeiro: Revista de Administração Pública, v. 41, n. 5, p. 863-885, 2007.
AZEVEDO, L. f. de; ALMEIDA NETO, T. Agroecologia: o "caminho" para o desenvolvimento rural sustentável no processo de extensão rural. Santa Maria: Revista Eletrônica em Gestão, Educação e Tecnologia Ambiental, v. 19, n. 3, p. 639-645, 2015.

BOAVENTURA, K. de J.; VAZ, W. F.; PORFÍRIO JÚNIOR, E. D.; SILVA NETO, C. de M. e; SOUZA, M. M. O. de. A agroecologia ontem, hoje e amanhã em terras tupiniquins: conceito, contexto e perspectivas. Anápolis: História Ambiental, Latinoamericana Y Caribeña. v. 8, n. 2, p. 180-209, 2018.

BORSATTO, R. S.; CARMO, M. S. do. A agroecologia como um campo científico. Porto Alegre: Revista Brasileira de Agroecologia, v. 8, n. 2, p. 4-13, 2013.

CANUTO, J. C. Agroecologia: princípios e estratégias para o desenho de agroecossistemas sustentáveis. Santa Cruz do Sul: Redes, v. 22, n. 2, p. 137-151. 2017.

DIAS, E. F.; MAZETTO, F. A importância da paisagem na geografia. Natal: Sociedade e Território, v. 26, n. 1, p. 92-106, 2014.

ECKERT, C. Orientações de sistematização de experiências. Porto Alegre: EMATER/RS-ASCAR, 2009. 46p.

HOLLIDAY, O. J. Para Sistematizar experiências. João Pessoa: UFPB, 1996. 216p.

LIMA, F. A. X. Construção de redes e agroecologia: o papel dos atores sociais no desenvolvimento rural. Campo Grande: Interações, v. 20, n. 1, p. 171-183, 2019.

LOPES, P. R.; ARAÚJO, K. C. SANTOS, LOPES, I. M. Sanidade vegetal na perspectiva da transição agroecológica. Rio de Janeiro: Revista Fitos, v. 13, n. 2, p. 178-194, 2019.

NODARI, R. O.; GUERRA, M. P. Agroecologia: estratégias de pesquisa e valores. São Paulo: Estudos Avançados, v. 29, n. 83, p. 183-207, 2015.

ORRIA, B.; LUISE, V. Innovation in rural development: "neorural" farmers branding local quality of food and territory. Roma: Italian Journal of Planning Practice, v. 7, n. 1, p. 125-153, 2017.

SANTOS, F. P. dos; CHALUB-MARTINS, L. Agroecologia, consumo sustentável e aprendizado coletivo no Brasil. São Paulo: Educação e Pesquisa, v. 38, n. 2, p. 469483, 2012.

SIMON, A. A. Sistematização de processos participativos: o caso de Santa Catarina. Porto Alegre; Revista Brasileira de Agroecologia, v. 2, n. 1, p. 540-543, 2007.

SOUSA, A. P. de; GOIÁS, B. S. de. Agricultura orgânica no Brasil como uma alternativa para o desenvolvimento agrícola. Anápolis: Revista de Eletrônica de Economia da Universidade Estadual de Goiás, v. 11, n. 1, p. 235247, 2015. 